\title{
The HPV school vaccination program: A discourse analysis of information provided to parents
}

\author{
Deborah Wise \\ University of Newcastle \\ Melanie James \\ University of Newcastle
}

\begin{abstract}
This paper reports a discourse analysis of the brochure titled 'Questions and answers (Q\&A) about HPV Vaccination Program: A prevention strategy for cervical cancer'. This brochure, part of a public relations /public information program is given to parents prior to HPV vaccination and, as such, is a primary source of information about HPV for this important audience. The research set out to answer the question: What are the discourses contained in the information given to parents about the NSW HPV school vaccination program? A critical discourse analysis of the Q\&A brochure found a strong contribution to a discourse of the risk of cancer and the discourse that HPV is sexually transmitted. The findings contribute to understanding of the role of public relations practitioners as 'discourse technologists' involved in the construction and maintenance of discourses and the ways in which this is achieved.
\end{abstract}

\section{Introduction}

Gardasil is the brand name for a vaccine that prevents the development of Human Papilloma Virus (HPV) types 16 and 18 (CSL Consumer Information, 2010) - the two types of HPV held to be responsible for causing approximately 70 per cent of all cervical cancers (Pharmaceutical Benefits Advisory Committee, 2007). Globally, Gardasil has been promoted as being the world's first anti-cancer vaccine, and its endorsement by the World Health Organisation (WHO, 2009) has ensured that to date more than 30 countries have approved Gardasil for use in female populations (Mandel, 2010). The World Health Organisation website proposes that widespread public education is needed if populations are to accept HPV vaccination (Parry, 2007). It is how this information is being communicated through the HPV school vaccination program brochure issued by the health department of the Australian state of New South Wales that is the focus of this research project.

In Australia, public relations practitioners play a key role in communicating health messages to the public. One manner in which this is managed is through the use of controlled messages, suggested by Hudson (2004) as being messages "over which the public relations practitioner maintains control of every aspect of the process - from message creation and crafting to final distribution” (p. 199). Adopting this tactic ensures that the public relations practitioner dictates the crafting of the message, how it will be produced, any visuals that will be incorporated, "and what kinds of colours, typefaces, fonts and papers may be chosen" (Hudson, 2004, p. 199). The information provided to parents of year seven NSW High 
School students (age approx 12-13 years), about the NSW Human Papilloma Virus (HPV) school vaccination program, is one example of a controlled message. Nonetheless, a review of the relevant literature suggested that in many instances, information about HPV vaccination was not being effectively communicated, with the possibility being that parents and their daughters may not be fully informed when making decisions about whether or not to vaccinate/be vaccinated.

The purpose of this research project was to explore the information provided to parents about the NSW HPV school vaccination program, from a public relations perspective, using critical discourse analysis. It is argued the findings from this study contribute to public relations research and scholarship by further demonstrating the value of critical discourse analysis as a methodology in the public relations field. The research strove to answer the question: What are the discourses contained in the information given to parents about the NSW HPV school vaccination program?

\section{Literature review}

Motion and Leitch (1996) drew on Foucault (1972) and Fairclough (1992, 1995) to argue that public relations practitioners are primarily discourse technologists because of their role in the "maintenance and transformation of discourse" (p. 298). Public relations practitioners are key members of this coterie of "discourse technologists" (Motion \& Leitch, 1996, p. 298) because of their role in maintaining and transforming sociocultural practices through the strategic deployment of public relations texts. However there is a "lack of critical work in public relations” that adopts discourse analysis as a research approach (Pieczka, 2008, p. 357). Public relations texts are tactical "discourse conventions that embody (at least implicitly) strategic imperatives" (Courtright \& Smudde, 2010, p. 59) and are usually deployed through the use of controlled messages that ideally result in an organisation's "target audiences getting exactly the communication it created for them and in the way it wanted them to get the communication" (Courtright \& Smudde, 2010, p. 62). The Q\&A brochure is one example of a controlled public relations message.

Motion and Leitch (1996) also argue the aim of public relations is to strategically position public relations texts so as to "maintain or to transform...sociocultural practices and the values and attitudes which support them and which they embody" (p. 298). Motion and Leitch (2007) suggest that applying a critical discourse framework to public relations practices , problematises "the role of public relations practitioners as they attempt to establish particular truths and alter power/knowledge relations” (p. 266). This, in turn, allows critical scholars to examine how discursive strategies are used to "advance the hegemonic power of particular groups" as they attempt to "gain public consent to pursue their organisational mission” (Motion \& Weaver, 2009, p. 50).

In Australasia, critical perspectives are typically integrated within a cultural studies framework (Sison, 2009), with communication seen as being a non-linear and dynamic cultural form in which discourse and the process of constantly renegotiating meaning are foregrounded (Curtin \& Gaither, 2005, p. 93). Discourses, from a Foucauldian perspective, are governed by analysable systems or structures that can be recognised "according to the rules of formation for all of the objects, concepts, subjects and strategies within discourse" (Motion \& Leitch, 2007, p. 264). These rules form systems of thought that determine what can be said and by whom, the allowable points of view, the positions from which speakers 
speak, "and the interests, stakes and institutional domains" that are represented through communicative networks (Motion \& Leitch, 2007, p. 264).

Discourses, moreover, "do not appear in a vacuum, but are in constant conflict with other discourses and other social practices” (Mills, 2002, p. 19). As such discourses may be "contested, resisted or transformed" - for example, through the work undertaken by public relations practitioners (Motion \& Leitch, 2007, p. 264). When discourse transformations occur (as in public relations campaigns) they create new rules that separate "out from among all the statements which are possible those that will be acceptable" (Foucault, 1972, cited in Motion \& Leitch, 2007, p. 264). Although remnants of the former discourse may remain, nevertheless "the underlying systems of thought and discourse are changed" (Motion \& Leitch, 2007, p. 264). When public relations practitioners successfully deploy discourse strategies, the resultant discourse transformation may achieve hegemonic status, whereby the "systems of thought that arise from particular societal configurations of power/knowledge relationships" result in a specific discourse becoming so pervasive it is perceived on a macro level as being common sense, and on a micro level as the "production and acceptance of particular truths” (Motion \& Leitch, 2007, p. 266). This study seeks to examine the discourse strategies used to achieve compliance and acceptance of the vaccination program.

In an Australian health communication study, Cooper Robbins, et al (2010) found the Australian HPV information given to parents was too complex, and consequently parents and adolescents were confused about HPV. A core theme that emerged from Cooper Robbins et al's (2010) study was a lack of knowledge about HPV vaccination including "what HPV is, how HPV is transmitted, and the HPV and cervical cancer connection" (p. 3398). Cooper Robbins et al (2010) suggest that based on their research, it is "essential to research and evaluate the design of information delivery, the content of messages and how this information is processed by individuals" (p. 3403). The research was undertaken as one step towards improving the understanding of information provided to parents about HPV vaccination.

\section{Research approach}

The study used a critical discourse analysis methodology to investigate, from a public relations perspective, the discourses contained in the brochure titled 'Questions and answers (Q\&A) about HPV Vaccination Program: A prevention strategy for cervical cancer'. Discourse analysis rejects the view of an objective reality to be studied separately from a reality constructed through discourse (Wood \& Kroger, 2000, p. 28). An advantage of using a discourse analysis methodology is that, whereas other qualitative methodologies "work to understand or interpret social reality as it exists, discourse analysis endeavours to uncover the way in which it is produced" (Phillips \& Hardy, 2002, p. 6). Critical discourse analysis (CDA) also differs from other forms of discourse analysis by:

Not just describing discursive practices, but also showing how discourse is shaped by relations of power and ideologies, and the constructive effects discourse has upon social identities, social relations and systems of knowledge and belief, neither of which is normally apparent to discourse participants (Fairclough, 1992, p. 12).

CDA is critical in that "it aims to show non-obvious ways in which language is involved in social relations of power and in ideology" (Fairclough, 2008, p. 229). There are no specified sets of procedures or methods for conducting a discourse analysis, nor does "constructionist theory ... directly guide DA in particular ways” (Nikander, 2008, p. 416). To remedy this 
dilemma, the approach adopted was that suggested by Phillips and Hardy (2002, p. 74) who recommend that researchers "need to develop an approach that makes sense in light of their particular study, and establish a set of arguments to justify the particular approach they adopt". In this study the textual analysis, an "educated guess at some of the most likely interpretations that might be made of that text" (McKee, 2003, p. 1), was the first step of the discourse analysis. Fairclough (2003) views discourse analysis as an essential part of textual analysis - arguing that, by itself, textual analysis is limited as meaning making requires looking at how texts are interpreted as well as the texts themselves (p. 15). Accordingly, Fairclough (2003) advocates that critical discourse analysis, in which texts are viewed "in terms of the different discourses, genres and styles they draw upon and articulate together" is valuable in this regard as it permits the analysis of texts at both a linguistic and more abstract level (p. 3).

The textual analysis comprises three levels. The first level looks at the text as a whole and analyses the brochure in terms of its genre, the way it is framed, the visual aids that have been used, the foregrounding, backgrounding and omission of information, presuppositions made by the writers, and the discursive differences contained in the text. The second level is a sentence-by-sentence analysis of the brochure and includes a discussion of the topicalisation techniques used, the agent-patient relations in the text as well as the deletion and/or omission of agents, and sentence-level presuppositions and insinuations. Also, at the sentence level, but at a more in-depth level is an analysis of the connotations and the labels that are used to carry connotations, as well as the register or the formality or informality of the text and the modality or the tone of statements as regards their authority. At the third level of analysis a contextualised interpretation is made about the text.

In this study the HPV vaccination information brochure, prepared by the NSW Department of Health and distributed throughout every public, Catholic, and independent High School in NSW, was selected because every parent/primary caregiver of a year seven girl at a NSW high school received a copy of this document. It is a primary source of information about the HPV school vaccination program for these audiences. The Q\&A brochure is an A4 doublesided document that is printed on both sides in a black 12 point sans serif font on a white background. The brochure contains twenty questions in bold print, and twenty answers that differ by not being in bold print. The questions and answers are framed within four boxes with bright pink borders that symmetrically divide the brochure into two columns per side. The header of the brochure reads "Questions \& answers (Q\&A) about HPV Vaccination Program: A prevention strategy for cervical cancer" and is printed in a black font similar to that used in the body, but it is substantially larger and, as with the questions, is in bold print The header is further differentiated from the body of the text by being set on a pale pink (3.5 $\mathrm{cm}$ wide) background. The same pink is also used as a background colour on the reverse side of the brochure in a box containing contact details for local Public Health Units. The Q\&A brochure is dated $10 / 2008$.

\section{Findings}

\section{Genre}

There are many different genres of consumer health materials and each is designed to target different lay audiences (Fieschi, Coiera, \& Li, 2004). The Q\&A brochure falls within the broad genre of consumer health information but more specifically it also falls within the genre of "patient broad" consumer health communication - a genre defined by Fieschi et al (2004) as being "health materials intended for patients and caregivers, but easily available to 
consumers...often formatted as a list” (p. 870). The Q\&A brochure conforms to the "broad patient" genre on several counts. Firstly, the intended use by caregivers (in this instance parents) is clearly signposted through the use of "my/your daughter" fifteen times throughout the body of the text. Secondly, there is very little background or contextual information, and the use of a question and answer format similarly "lists" information. Using a question and answer format also means the brochure is not written in a feature or news style. Thirdly, as the contents of the brochure are freely available in digital form on the NSW Department of Health's website and are also distributed throughout every NSW high school, the brochure is easily available to its intended audience of parents.

The use of a question and answer format instead of a list suggests a rationale for going beyond the normal boundaries of the genre. Perhaps the most obvious reason is provided by Treadwell and Treadwell (2004) who say "for issues that require explanations ... a direct question and answer (Q\&A) approach is often a good way to get across all of the details" (p. 286). Question and answer formats are also usually used in fact sheets, and borrowing from this genre could suggest to readers that the Q\&A brochure is similarly factual. These rationales aside, encoding information in a question and answer format undoubtedly serves the purposes of the NSW Department of Health as it allows the brochure's writer(s) to decide not only what questions will be asked, but also how they will be answered. Accordingly, while it could be argued that using a Q\&A format is merely a technique used to fulfil the brochure's cultural purpose of educating parents, it could also be argued that the brochure is as much about telling parents what they need to know, as it is about telling them what they (assumedly) want to know.

\section{Framing}

Conveying to parents that what they want to know is the same as what they need to know is largely achieved through framing techniques. Each of these framing techniques either limits or defines the meaning of a message and in so doing shapes "the inferences that individuals make about the message" (Hallahan, 1999, p. 207). The key frame being conveyed in the brochure is that of the high risks associated with not being vaccinated, versus the benefits of being vaccinated. This is made evident in the first column of the brochure that deals with the risks associated with HPV infection. Put succinctly, these are that women have a high risk of contracting an often-symptomless sexually transmitted infection known to cause most cervical cancers. Moreover, although most women clear the virus and do not get cervical cancer, condoms (a device often recommended as protection against sexually transmitted viruses) offer "limited" protection in this instance.

The second column of the brochure is mostly dedicated to discussing the safety and benefits of the vaccine in terms of what it contains, how many doses are needed, how long the vaccine lasts, as well as any side effects including the possibility of anaphylaxis - a potentially severe allergic reaction. The use of this frame means the brochure effectively fulfils one of the first aims of persuasive health messages - namely that a message should "convince individuals (a) they are susceptible to a severe threat and (b) adopting an easy and feasible recommended response would effectively avert the threat” (Witte, 1995, p. 146).

\section{Visual aids}

The brochure contains no photographs, however there are several visual aids that are used to attract readers' attention. One of the most obvious is the use of a question and answer format that, by breaking information down into 'bite size chunks', has the effect of bulleting (albeit without bullet points) and this makes information appear more inviting because it is short (Treadwell \& Treadwell, 2005, p. 283). Setting the questions in a bold print also does more 
than distinguish the questions from the answers - it has the effect of making each question appear as a sub-title. The other technique used to attract the audience's attention is the HPV brochure's pink heading. As Witte (1995) points out, "messages must be culturally, demographically, and geographically appropriate if they are to influence the audience as intended” (p. 146). In Australia, as in many Westernised cultures, pink is a cultural symbol for femininity and the use of pink is a cultural cue that the Q\&A brochure is a document about females for female readers.

\section{Foregrounding/backgrounding}

The brochure is framed so that parents are presented with a risk or a threat (HPV infection and cervical cancer) before being offered a solution to averting that risk/threat (HPV vaccination). This is achieved by foregrounding the risks associated with not being vaccinated and the effectiveness of the vaccine, ahead of other questions parents may have about vaccination. For example, although possible side effects associated with vaccination are answered in response to the question "What are the side effects of vaccination?" this is effectively backgrounded by being placed ninth in the brochure.

On the reverse side of the brochure, and also effectively backgrounded, is information about the ongoing need for pap smears after vaccination, and that parents, in agreeing to vaccinate their daughters, are also agreeing to their daughter's information being transferred to two other government agencies.

\section{Omission}

'Patient broad' consumer health communications do not typically include background or contextual information (Fieschi et al., 2004) so it is difficult to critique the HPV brochure on these grounds. However, one obvious omission made in the HPV brochure is that it fails to mention that the vaccine is also currently approved for use in males aged 9-15 years (CSL, 2010) and also, like females, males can not only contract HPV, but HPV in males can similarly cause cancer. Perhaps most important is the omission that males act as the vectors for HPV infection through sexual activity, (Taira, Neukermans \& Sanders, 2004). The noninclusion of this information in a genre that is supposedly about educating the public raises important questions about why HPV infection is portrayed in the brochure as being solely a female problem and why, in a wider societal context, boys are not being vaccinated as well.

\section{Presupposition}

The way the brochure is framed presupposes that the questions of most concern to parents are about the risks associated with HPV infection, rather than the risks associated with vaccination. In Australia, as in many developed Western nations, there has been widespread media coverage about the introduction of the vaccine, with reports about the side effects (and on a few occasions reports of deaths) that apparently resulted from HPV vaccination leading to some members of the community becoming outspoken opponents of the vaccine, and in some instances advocating against all vaccination programs generally. There is also no discussion of vaccination prior to recommending it as a preventative for HPV infection - the presupposition being that parents are already knowledgeable about, and accepting of, vaccination as a routine medical intervention. The brochure can also be seen as adhering to the pre-eminent Western medical model in which, as L'Etang (2008) argues the presupposition is that human illnesses are the direct result of causes that can be located in the human body. 


\section{Discursive differences}

Parents (or laypersons) are discursively positioned in the brochure as the questioners seeking answers and accordingly as those lacking knowledge. This is suggested in the text through the voice of the parent that asks relatively simple medical questions about HPV in relation to their daughter/child. Medical science on the other hand, is discursively positioned as the answerers and possessors of that knowledge. However, whereas the voice of the parent is made obvious through the use of "my child/daughter" throughout the text, the voice of the answerer is devoid of a writer's presence. Although it could be argued that, in scientific writing (and in academic writing generally), the use of a neutral and anonymous third person voice is the norm, nonetheless the lack of an identity in the voice of the answerers results in conveying an impersonal scientific discourse, and as such the answers are portrayed as being an objective presentation of ideas that transcend any individual voice (Hyland, 2002). In so doing, the questioners (parents/guardians) are discursively positioned as the voice of the helpless ordinary layperson, while the answerers are positioned as "the voice of authority and expertise representative of the scientific community” (Huckin, n.d., p. 6).

\section{Sentence level topicalisation}

The frame of the risks of HPV infection versus the benefits of vaccination is supported in the text by repeating the topic in the following sentences. As such, the importance of a topic is reinforced through a form of sentence level foregrounding, as the following example demonstrates.

Topic - Risks of HPV infection:

- HPV is the name given to a group of viruses that cause skin warts, genital warts and some cancers ...

- Two particular types of HPV are responsible for causing up to $80 \%$ of cervical cancers (cancer of the cervix) in Australia

- HPV infection is usually without symptoms

- It is estimated that up to 79\% of women in Australia will be infected with HPV

- Women can be infected with HPV through sexual contact

- HPV can be transmitted during sex and genital skin-to-skin contact

- There is no cure for HPV infection but there is treatment available for the effects of the virus, such as genital warts and abnormal changes to the cervix.

It can be deduced from this sentence level topicalisation that the slant being suggested in the brochure concerns HPV infection in terms of genital warts, the cervix, cancer, infection, sex, and women. Interestingly, the most topicalised individuals are daughters with the term 'daughter' used fifteen times throughout the brochure.

\section{Sentence level agency}

Despite the prominent topicalisation of daughters, they are nonetheless depicted in the brochure as the (powerless) patients having things done to them, and parents/guardians are depicted as the agents with the power to determine what will be done to them. This is manifested in the response to the question, "is vaccination compulsory for this campaign?" that states:

No ...all parents/guardians can choose whether or not to sign the consent form and have their child vaccinated. Only those children with a consent form completed and signed by a parent/guardian will be vaccinated. Do not return the consent form if you do not wish your daughter to be vaccinated [original emphasis]. 
This statement achieves three things. Firstly, it stresses the powerlessness of daughters by referring to them as a child/children and in so doing surrenders them to being too young to make their own decisions. Secondly, it stresses the power of parents/guardians as the decision-makers. Thirdly, in stressing the power and agency of parents, attention is steered away from who is doing the vaccinating. This omission of an agent is also evident in response to the questions:

- Will my daughter's information be transferred to any other organisation?

- Why will my daughter's health information be linked to the National Cervical Screening Program?

The brochure states that:

- Your daughter's health information will be transferred to the National HPV Vaccination Program Register and linked to the National Cervical Cancer Screening program.

- Health information collected will be used to evaluate the impact of the HPV Vaccination program on cervical cancer rates.

In both of these statements it is not made clear who the agent or agency is that is transferring and collecting their daughter's health information. Rather, by highlighting once again the apparent power of parents/guardians to decide, attention is diverted away from the fact that by agreeing to vaccination, parents are also agreeing to their daughter's health information being shared amongst several other institutions, and this raises further questions about the level of power parents possess in this context.

\section{Sentence level presuppositions}

At the sentence level of the brochure a key presupposition is contained in the question "Why should my daughter be vaccinated?" By not posing the question as, for example, 'should my daughter be vaccinated?" the presupposition is that daughters should be vaccinated. Furthermore, included in the reasons given for vaccination, is the statement "there is no cure for HPV infection". This statement not only implies that HPV needs curing, it contradicts an earlier claim made in the brochure that "most women who have HPV clear the virus naturally”.

\section{Sentence level insinuations}

At the sentence level of the text, in the statement that "HPV infections of the cervix usually do not cause any symptoms", the insinuation being made is that because HPV is usually without symptoms, women will not know if they have, or have had, an HPV infection. This insinuation is important because it infers that all women are at risk, and this supports the key frame of the high risks associated with not being vaccinated, versus the benefits of being vaccinated. Another insinuation being made in the brochure is contained in the statement that "women can be infected with HPV through sexual contact and it is estimated that up to 79\% of women in Australia will be infected with HPV at some point in their lives". The insinuation being made in this sentence is that $79 \%$ of women will get sexually transmitted HPV and that this will be a form of HPV likely to cause cancer. However, as the Department of Health and Ageing (2011a) states, "There are over 100 different types of HPV, including some that affect the genitals" and of these "only a few are considered high risk and are linked to cervical cancer” (Department of Health and Ageing, 2011b). 


\section{Words and phrase level connotations}

Words and phrases carry special meanings or connotations in the brochure. Amongst the techniques used by the brochure's writers is the repetition of the word "cancer" a total of five times in the first two questions and answers, and once again in the heading of the brochure. Cancer as a word conjures different meanings for different people but in most instances the connotation is negative, and in most people's minds is associated with long-term disease, invasive and debilitating treatments, and often results in death. Taken in the context of the brochure, the connotation being made between cancer and vaccination provides a powerful argument for vaccination.

Labels also carry connotations and the brochure uses different labels to connote different things about females. For example, in the first three answers to questions about HPV, the term "women" is used to refer to females. The following question then moves from this term for females with its connotations of maturity to ask "Why should my daughter be vaccinated?" The term daughter arguably connotes an emotional response in parents/guardians. In the answer to this question females are then labelled as "young women" ("Even if young women have started sexual activity, there is a benefit to being vaccinated ...”). By using the term young women instead of daughter the connotation is less personal (i.e. it is not your daughter engaging in sexual activity) and moreover that as "young women" they are mature enough to do so.

\section{Register}

The question "Will boys be vaccinated at school?" is the only reference made to males in the brochure. Moreover the connotation associated with the term boys is one of immaturity and this is especially interesting because females are never referred to in the brochure as "girls". One way in which to demonstrate the power of labels is to replace the term young women (as in the previous example) with the term "girls" (i.e. even if girls have started sexual activity...). In this example the connotation that girls has with immaturity would have suggested something quite different from the maturity that young women connotes. By the same token, if the writers had used young men (i.e. will young men be vaccinated at school?) the connotation is again quite different from that connoted by boys.

Most of the text in the brochure is written in a semi-formal scientific register to convey information simplified for a lay audience, whilst also suggesting medical authority. For example the lay term "skin" is used instead of the medical term "epidermis", and other names such as warts, cancer, infected/infection, virus, body fluid, blood, cure, abnormal, treatment, pain, swelling, side effects, injection, fever, unconsciousness, death, pregnant and vaccinate are for the most part readily known lay terms that do not require any specialised medical knowledge to be understood. The brochure also does not use slang terms such as "bug" for virus or "fanny" for genital and this is because the use of slang terms could be seen to have the potential to undermine the construction of medical authority.

\section{Modality}

Modality refers to "the tone of statements as regards their degree of certitude and authority (and) it is mainly carried by words and phrases" (Huckin, n.d., p. 8). In the phrases, "two particular types of HPV are responsible for causing up to 80 per cent of cervical cancers" and "up to 79 per cent of women will be infected", statistics are used to convey scientific certainty. Statistical information, as Crotty (1998) points out, is not arrived at speculatively but rather through what has been scientifically observed. Statistics are also juxtaposed throughout the brochure against phrases such as "a group of viruses" and "most women who have HPV clear the virus naturally”. The use of these terms, as opposed to scientifically 
arrived at statistical "facts", results in a modality that provides certitude about the risk of getting cervical cancer, but is much more vague about the numbers of types of HPV, whether or not a women will have any symptoms, and whether or not women will clear the virus naturally. For some readers the uncertainty suggested through the use of "usually" and "most", together with the certainty of statistical evidence, may induce them to think they (and their daughters) are at more risk of getting cancer than not.

Overall the textual analysis indicated that the high risks of cervical cancer were foregrounded, while other aspects were backgrounded. Also backgrounded was the fact that in agreeing to vaccination, a girl's information is automatically transferred to several agencies. Although it is not stated in the brochure, one of the conditions of the vaccine being placed on the Australian Pharmaceutical Benefits Scheme was that a registry of names be set up in case future booster vaccinations were needed. If this scenario eventuates, and girls need to have booster injections, it will raise further questions about the cost effectiveness of a vaccination program in a country that already has one of the lowest rates of cervical cancer due to its pap screening program.

\section{Key discourse at work in the brochure: risk}

In the textual analysis of the brochure, an over-riding discourse of risk was discussed. Initially, a risk discourse is made apparent in the title of the brochure that states the HPV vaccination program is "a prevention strategy for cervical cancer". The use of the term prevention means something has to be stopped from happening - the counter inference being that cervical cancer will happen without preventative measures being taken. Gardasil is a vaccine that helps prevent two types of HPV that cause genital warts and two types of HPV that are linked to cervical cancer, however it is not a vaccine for cervical cancer per se. Given the title does not mention that the vaccine is a prevention strategy for genital warts, and that it is only a prevention strategy for cervical cancer, suggests a strategic intention to highlight a discourse of the risk of cancer.

The risk of cancer discourse established in the title is supported in the first two questions and answers of the brochure. Answer one repeats that HPV can cause "some cancers" and question two then asks, "What is the link between HPV and cervical cancer?" The response to this question states that "two particular types of HPV are responsible for causing up to 80 per cent of cervical cancers (cancer of the cervix) in Australia...most women who have HPV clear the virus naturally and do not develop cervical cancer". Despite this latter statement supposedly offering readers some reassurance, the term "cancer" has already been used six times in the title and opening paragraphs of the document. As numerous studies have found, acceptability of HPV vaccination is improved if links are made between HPV and cervical cancer (Brabin, Roberts, Farzaneh \& Kitchener, 2006; de Visser \& McDonnell, 2008), foregrounding a risk of cancer from HPV arguably results in this being the key meaning that readers are meant to construct from the Q\&A brochure.

The discourse of risk is also communicated by the descriptions in the brochure about how HPV is spread. Questions two and three contain the statements that "women can be infected with HPV through sexual contact" and "HPV can be transmitted during sex". Moreover the brochure then states that "condoms offer limited protection". The use of condoms as a preventative method against sexually transmitted diseases is a prominent discourse in society and the inclusion of this statement in a discussion about the sexual transmission of HPV serves to heighten a discourse of risk. 
A discourse of risk is further suggested in the dual claims made in the brochure that "up to 79 per cent of women in Australia will be infected with HPV at some point in their lives" and "two particular types of HPV are responsible for causing up to 80 per cent of cancers". In both of these phrases the use of statistics conveys a discourse of risk based on scientific evidence. Despite both statements also using "up to" (up to 79 per cent ... up to 80 per cent) it is likely that the average reader will overlook this proviso and instead will only recollect the certain risks that statistics convey.

The brochure also states that most HPV infections spontaneously clear. However the use of "most" is also telling. This is because the Department of Health and Ageing (2006) states on its website that in "98 per cent of cases, HPV clears by itself". The non-inclusion of this scientifically based statistic about the (even higher) 98 per cent chance of not getting cervical cancer from HPV, and the inclusion of statistics to reinforce the risks of getting cervical cancer, suggests a motive of wanting to promote a discourse of the risks of cervical cancer ahead of the low risk of this actually occurring.

\section{Conclusion}

The primary discourse constructed in the brochure is that of the high risks associated with not being vaccinated (i.e. cancer), versus the benefits of being vaccinated. Although there are particular discourses in operation through the brochure and some of these could be seen as manipulative, it could also be argued that there is no need to change the content, or the layout, or the method of delivery of the brochure, when it is succeeding in convincing parents to agree to vaccinate their daughters - in this regard the Q\&A brochure can be regarded as an example of a successful piece of public relations communication. The national HPV vaccination program in Australia has been an undoubted success (Smith, Canfell, Brotherton, Lew \& Barnabas, 2008, p. 1854). In NSW, the Department of Health and Ageing found that during the first year of the program, coverage of 70 per cent or more was achieved "among almost all school cohorts vaccinated” (Department of Health and Ageing, 2008).

In concluding that the Q\&A brochure is slanted towards promoting a discourse of the risk of cancer, the question of the centrality to the construction of this discourse is the role of public relations practitioners who, as Motion and Leitch (1996) suggest, are discourse technologists because of their role in maintaining and transforming discourses. By problematising the discourses in the brochure, any "truths" espoused in the text, as well as power disparities between institutions and individuals can be explored and further research could examine motivations and techniques that are used by public relations practitioners working in the health communication field. Another question that future research should address is in whose interests is the discourse of risk working - vaccine producers, researchers, or the population? So, although commissioned by a government agency, in whose interests are public relations practitioners working?

A further aim of this study was to contribute to scholarly knowledge about conducting critical discourse analysis in relation to public relations texts and the authors trust that this study succeeds in doing this.

\section{References}

Brabin, L., Roberts, S., Farzaneh, F. \& Kitchener, H. (2006). Future acceptance of adolescent human papillomavirus vaccination: A survey of parental attitudes. Vaccine, 24, 3087-3094.

doi:10.1016/j.vaccine.2006.01.048 
Cooper Robbins, S., Bernard, D., McCaffery, K., Brotherton, J., Garland. S. \& Skinner, R. (2010). Is cancer contagious? Australian adolescent girls and their parents: making the most of limited information about HPV and HPV vaccination. Vaccine, 28, 3398-3408. doi:10.1016/j.vaccine.2010.02.078

Courtright, J., \& Smudde, P. (2010). Recall communications: discourse genres, symbolic charging, and message design. International Journal of Strategic Communication, 4 (1), 58-74. doi: $10.1080 / 15531180903416051$

CSL. (2010). Consumer information brochure. Retrieved from http://www.csl.com.au/s1/cs/auhq/1196562765747/Web_Product_C/1196562633137/ProductDetai l.htm

Curtin, P., \& Gaither, T. (2005). Privileging identity, difference, and power: the circuit of culture as a basis for public relations theory. Journal of Public Relations Research, 17(2), 91-115. doi:10.1207/s1532754xjprr1702_3

De Visser, R., \& McDonnell, E. (2008). Correlates of parents' reports of acceptability of human papilloma virus vaccination for their school-aged children. Sexual Health, 5(4), 331-338. doi: 10.1071/SH08042

Department of Health and Ageing. (2006). Australian government funding of Gardasil, fact sheet about the Human Papilloma Virus (HPV) vaccine. Canberra, Australia. Retrieved from http://www.health.gov.au/internet/main/publishing.nsf/Content/gardasil_hpv.htm

Department of Health and Ageing. (2008). Interim estimates of Human Papilloma Virus vaccination coverage in the school-based programme in Australia. Communicable Diseases Intelligence, 32(4). Canberra, Australia. Retrieved from http://www.foodsecretariat.health.gov.au/internet/main/publishing.nsf/Content/cda-cdi3204i.htm

Department of Health and Ageing. (2011a). National Cervical Screening Programme: HPV (human papillomavirus). Canberra, Australia. Retrieved from http://www.cancerscreening.gov.au/internet/screening/publishing.nsf/Content/cervical-about

Department of Health and Ageing. (2011b). National Cervical Screening Programme: National information statement of HPV (human papillomavirus). Retrieved from

http://webcache.googleusercontent.com/search?q=cache:bbEK09pUtFAJ:www.health.gov.au/inter net/screening/publishing.nsf/Content/nis-

hpv+'linked+with+cervical+cancer'+site:health.gov.au\&cd=1\&hl=en\&ct=clnk\&gl=au\&client=saf ari\&source=www.google.com.au

Fairclough, N. (1992). Discourse and social change. Cambridge, UK: Polity Press.

Fairclough, N. (2008). The discourse of new labour: critical discourse analysis. In M. Wetherell, S. Taylor, \& S.J. Yates (Eds.), Discourse as data: A guide for analysis (pp. 229-266). London, UK: Sage.

Fieschi, M., Coiera, E. \& Li, Y. (Eds.) (2004). Medinfo 2004: Proceedings of the 11th World Congress on medical informatics. Amsterdam, The Netherlands: IOS Press.

Hallahan, K. (1999). Seven models of framing: Implications for public relations. Journal of Public Relations Research, 11(3), 205-242. doi:10.1207/s1532754xjprr1103_02

Huckin, T. (no date). Social approaches 6: critical discourse analysis. English as a foreign language publication catalogue, English language programmes, US Department of State. Retrieved from http://eca.state.gov/education/engteaching/pubs/BR/5111FRM.htm

Hudson, M. (2004). Tactics. In J. Johnson \& C. Zawawi, (Eds.), Public relations theory and practice (pp. 197-231). Crows Nest, NSW: Allen \& Unwin.

Hyland, K. (2002). Options of identity in academic writing. ELT Journal, 56(4), 351-358. doi:10.1093/elt/56.4.351

Johnston, J., \& Zawawi, C. (Eds.). (2004). Public relations theory and practice ( $2^{\text {nd }}$ ed.). Crows Nest, NSW: Allen \& Unwin.

L’Etang, J. (2008). Public relations. concepts, practice and critique. London: Sage.

Mandel, C. (2010). Update on new vaccine introduction 2009. 5th global immunization meeting 1-3 February, Geneva, Switzerland. Retrieved from www.who.int/entity/immunization_delivery/systems_policy/NUVI_GIM2010.pdf

Mills, S. (2004). Discourse: the new critical idiom. New York, NY: Routledge. 
Motion, J., \& Leitch, S. (1996). A discursive perspective from New Zealand: Another world view. Public Relations Review, 22(3), 297-309. doi:10.1016/S0363-8111(96)90051-X

Motion, J., \& Leitch, S. (2007). A toolbox for public relations: the oeuvre of Michel Foucault. Public Relations Review, 33 (3), 263-268. doi:10.1016/j.pubrev.2007.05.004

Motion, J., \& Weaver, C.K. (2009). A discourse perspective for critical public relations research: Life sciences network and the battle for truth. Journal of Public Relations Research, 17(1), 49-67. doi:10.1207/s1532754xjprr1701_5

Nikander, P. (2008). Constructionism and discourse analysis. In J. Holstein \& J. Gubrium (Eds.), Handbook of constructionist research (pp. 413-428). New York, NY: The Guilford Press.

Parry, J. (2007). Vaccinating against cervical cancer. Bulletin of the World Health Organisation (BLT), 82(2), 85-160. Retrieved from http://www.who.int/bulletin/volumes/85/2/07020207/en/index.html

Phillips, N., \& Hardy, C. (2002). Discourse analysis: investigating processes of social construction, Thousand Oaks, CA: Sage.

Pieczka, M. (2008). Paradigms, systems theory and public relations. In J. L'Etang \& M. Pieczka (Eds.), Public relations: critical debates and contemporary practice (pp. 331-358). Marwah,NJ: Lawrence Erlbaum.

Sison, M. (2009). Theoretical contexts. In J. Chia \& G. Synnott (Eds.), An introduction to public relations: from theory to practice (pp. 54-89). South Melbourne: Oxford University Press.

Smith, M., Canfell, K., Brotherton, J., Lew, J. \& Barnabas, R. (2008). The predicted impact of vaccination on human papillomavirus infections in Australia. International Journal of Cancer, 123, 1854-1863. doi:10.1002/ijc.23633

Taira, A., Neukermans, C. \& Sanders, G. (2004). Evaluating human papillomavirus vaccination programes. Emerging Infectious Diseases, 10(11), 1915-1923. Retrieved from http://www.cdc.gov/ncidod/EID/vol10no11/04-0222.htm

Treadwell, D., \& Treadwell, J. (2004). Public relations writing: principles in practice. Thousand Oaks, CA: Sage.

Witte, K. (1995). Fishing for success: Using the persuasive health message framework to generate effective campaign messages. In E. Maibach \& R. Parrott (Eds.), Designing health messages: approaches from communication theory and public health practice (pp. 145-168). Thousand Oaks, CA: Sage.

Wood, L., \& Kroger, R. (2000). Doing discourse analysis: methods for studying action in talk and text. Thousand Oaks, CA: Sage

World Health Organisation. (2009). WHO position on HPV vaccines [Conference report]. Vaccine, 27, 7236-7237. doi:10.1016/j.vaccine.2009.05.019

* Deborah Wise B. Comm (Hons) works as a sessional academic tutoring in public relations at the University of Newcastle, Australia. She is a current a M. Phil student at the University of Newcastle.

* Melanie James PhD, M (Journalism), BA Comm (Hons), MPRIA is a Senior Lecturer at the University of Newcastle, Australia. She took up an academic role in 2006, after a 20-year professional career spanning public relations, professional writing and journalism. 